\title{
DISCOVERY LEARNING BERBANTUAN DEMONSTRASI UNTUK MENINGKATKAN KREATIVITAS: ACTION RESEARCHDI SEKOLAH DASAR
}

\author{
Liling Arlindawati \\ SDN Ledokwetan I Bojonegoro \\ Email: lilingarlindawati@gmail.com
}

\begin{abstract}
Informasi Artikel Abstrak
Kata kunci:

Demonstrasi, discovery

learning, kreativitas.

Diterima: $10-11-2020$

Disetujui: $13-11-2020$

Dipubikasikan: 15-11-2020

Tujuan penelitian ini adalah menganalisis penerapan discovery learning berbantuan demonstrasi untuk meningkatkan kreativitas. Penelitian ini merupakan action research di SDN Ledokwetan I Bojonegoro. Subjek penelitian adalah siswa kelas VI SDN Ledokwetan I Kec.Bojonegoro Kab. Bojonegoro. Penelitian ini memerlukan 2 Siklus dengan siswa sebanyak 18 siswa. Penelitian dilaksanakan dengan dua kali siklus. Setiap siklus meliputi perencanaan, pelaksanaan, pengamatan dan refleksi. Data dikumpulkan dengan melakukan tes dan observasi. Teknik pengumpulan data melalui tes hasil belajar. Hasil penelitian menunjukkan bahwa discovery learning berbantuan demonstrasi dapat meningkatkan kreativitas siswa sekolah dasar dalam menghasilkan energi alternatif listrik.
\end{abstract}

\section{PENDAHULUAN}

Pada era 4.0, individu hidup di dunia yang serba instan dengan berbagai perubahan yang pesat terjadi. Perubahan itu terjadi dalam berbagai aspek kehidupan manusia. Perubahan tersbut menuntut orang memiliki kesiapan dan cara-cara baru untuk menghadapi berbagi perubahan yang ada. Oleh karena itu, orang perlu mengembangkan kreativitas agar bisa menghadapi perubahan di zaman ini. Dengan adanya kreativitas, individu akan memiliki kemampuan yang lebih.

Kreativitas merupakan kemampuan seseorang mengungkapkan kelancaran, keluwesan (fleksibilitas), dan orisinalitas dalam berpikir, serta mengelaborasi sebuah gagasan (Siswono, 2019). Conny Semiawan (dalam Rusdi, 2018) mengemukakan bahwa kreativitas merupakan kemampuan untuk memberikan ide baru dan menerapkannya dalam pemecahan masalah. Kreativitas meliputi ciri-ciri aptitude seperti kelancaran, keluwesan, dan keaslian dalam pemikiran, maupun ciri-ciri non aptitude seperti rasa ingin tahu, senang mengajukan 
pertanyaan, dan selalu ingin mencari pengalaman-pengalaman baru. Kreativitas akan meningkatkan apresiasi akan berbagai gagasan orang lain. Siswa yang kreatif pasti bisa menerima dan menghargai ide-ide orang lain, tanpa memandang siapapun yang memberikan ide tersebut. Kreativitas akan meningkatkan semangat berprestasi.

Hasil observasi peneliti sebagai guru di SDN Ledokwetan I Bojonegoro, menunjukkan adanya permasalahan sebagai berikut :kurangnya kreativitas belajar siswa dibuktikan sebagian besar siswa tidak memiliki rasa ingin tahu yang besar, kurang memiliki keberanian dalam menyampaikan pendapat, kurangnya wawasan yang berkaitan dengan materi ketika menyampaikan gagasan atau usulan, hal tersebut dipengaruhi orang lain bukan merupakan pendapat sendiri, gagasan atau usulan kurang tepat untuk memecahkan suatu masalah dan kurangnya unsur inovasi dalam gagasan.

Sebagai guru kita hendaknya peka terhadap masalah-masalah yang timbul dan berusaha agar kreativitas siswa tidak menurun dalam pembelajaran terutama pembelajaran daring kita jalani. Kita harus jeli dalam perencanaan pembelajaran terutama dalam pemilihan model pembelajaran. Penggunaan model yang tepat dapat membantu siswa dalam meningkatkan kreativitas siswa (Fanny, 2019). Salah satu model pembelajaran yang dapat dijadikan alternatif pilihan adalah discovery learning.

Discovery learning adalah model pengembangan kemampuan belajar aktif pada siswa agar bisa investigasi dan mendapatkan ilmu secara mandiri. Dengan belajar aktif ini siswa juga bisa dilatif berpikir secara analisis dan pemecahan masalah sehingga ilmu pengetahuan bisa bertahan lama dalam diri siswa (Trung, 2014). Aktivitas pembelajaran discovery learning perlu dipadukan dengan metode demonstrasi, dimana materi diberikan dan dipraktikan langsung kepada siswa. Selanjutnya siswa dianjurkan untuk mengelola materi tersebut secara mandiri. Dimana mereka harus bisa menemukan konsep berdasarkan data atau informasi dengan cara penelitian (Rahman, 2017). Hasil penelitian Prasasti (2019) menunjukkan bahwa model discovery learning dapat meningkatkan hasil belajar. Beberapa hasil penelitian menyatakan bahwa model discovery learning efektif terhadap motivasi belajar siswa sekolah dasar (Aisyah, dkk, 2017; Marliyah, 2019; Susmiati, 2020). Sejalan dengan itu, hasil penelitian Istiqomah (2019) menyatakan metode demonstrasi dapat membantu siswa untuk berpikir kreatif dalam menyelesaikan masalah.

Berdasarkan pemaparan latar belakang di atas, peneliti melaksanakan Action Research dengan bertema "Penerapan Discovery Learning Berbantuan Demonstrasi Untuk Meningkatkan Kreativitas Siswa Dalam Menghasilkan Energi Alternatif Listrik Sekolah Dasar".

\section{METODE}

Penelitian ini merupakan action research yang bertujuan untuk mengetahui bagaimana pelaksanaan penerapan discovery learning berbantuan demonstrasi dalam siklus berulang pada muatan pelajaran IPA. Subjek penelitian adalah siswa kelas VI SDN Ledokwetan I Kec.Bojonegoro Kab. Bojonegoro. Penelitian ini memerlukan 2 Siklus dengan siswa sebanyak 18 siswa. 
Secara umum ada empat tahap dalam penelitian tindakan kelas, yaitu perencanaan, tindakan, pengamatan, dan refleksi. Berikut gambar metode action research dalam penelitian ini.

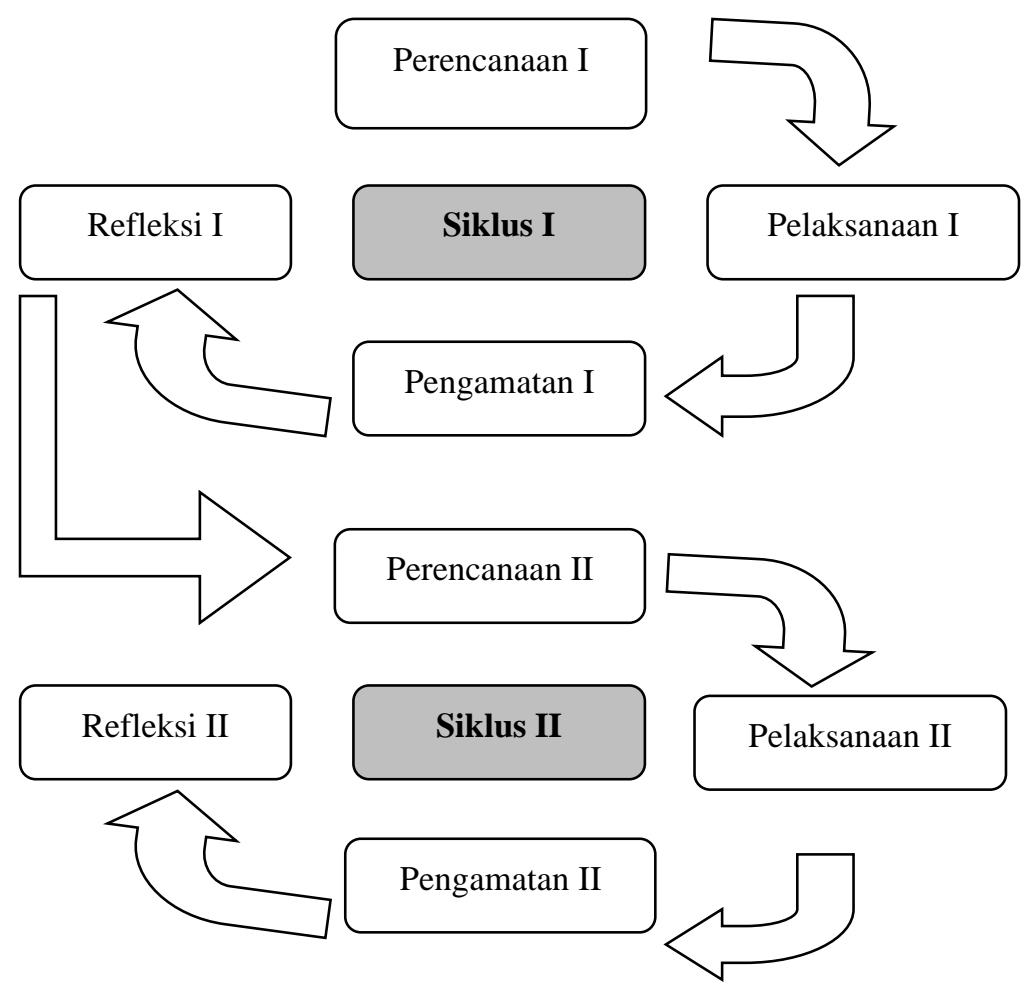

Gambar 1. Metode Action Research

a. Perencanaan

Tahap ini adalah menentukan materi IPA sumber energi alternatif listrik Tema 4 Globalisasi, Subtema

Globalisasi dan Cinta Tanah Air siswa dengan model discovery learning berbantuan demontrasi. Peneliti juga menyusun scenario pembelajaran dengan menyusun RPP, LKPD, media dan bahan ajar, indikator pencapaian kompetensi, serta membuat format observasi guru dan siswa.

b. Pelaksanaan tindakan

Proses pelaksanaan pembelajaran IPA dengan model discovery learning berbantuan demontrasi. Proses pembelajaran di sini sejak awal sampai akhir pelaksanaan pembelajaran dengan model discovery learning berbantuan demontrasi. Tidak hanya saat penerapan model discovery learning saja, tetapi secara menyeluruh dalam satu rangkaian pembelajaran yaitu persiapan, proses, dan evaluasi hasil pembelajaran. Fokus utama dalam penelitian ini adalah penggunaan model discovery learning berbantuan demontrasi pada siswa kelas IV SDN Ledokwetan I Kec.Bojonegoro Kab. Bojonegoro.

c. Pengamatan (Observasi) 
Observasi di sini berfungsi untuk mendokumentasikan pengaruh tindakan terhadap kreatifitas siswa. Observasi dilakukan saat proses pembelajaran IPA dengan model discovery learning berbantuan demontrasi.

d. Refleksi

Refleksi adalah mengingat kembali sesuatu tindakan persis dengan yang telah dicatat dalam observasi pada pengalaman mengajar di kelas IV SDN Ledokwetan I Kec.Bojonegoro Kab. Bojonegoro. Peneliti mengumpulkan dan menganalisis data yang diperoleh dalam tahap pelaksanaan observasi. Pada tahap ini data yang diperoleh dari pengalaman mengajar dianalisis dan dipakai untuk refleksi. Berdasarkan pengalaman mengajar dapat diketahui hasil adanya tindakan, yang dapat digunakan dalam menentukan perencanaan dan tindakan selanjutnya sebagai perbaikan pada siklus kedua. Hal ini bertujuan untuk melakukan penyempurnaan pada siklus kedua, ketika belum dapat mencapai tujuan yang diharapkan.

\section{HASIL DAN PEMBAHASAN}

\section{Deskripsi Siklus I}

a. Perencanaan

Pada perencanaan pembelajaran siklus I ini dilaksanakan pada hari Selasa tanggal 27 Oktober 2020 pukul 08.00 - 09.00, dengan materi sumber energi alternatif listrik Tema 4 Globalisasi Subtema Globalisasi dan Cinta Tanah Air siswa kelas VI SD Negeri Ledokwetan I Bojonegoro dengan diberikan video tutorial youtube tentang percobaan energi alternatif listrik dengan tenaga kentang. Adapun langkah - langkah yang dilaksanakan sebagai berikut :

1) Menyusun Rencana Pelaksanaan Pembelajaran

2) Menyusun instrumen soal

3) Menyiapkan lembar jawaban

4) Menyiapkan lembar penilaian siswa

5) Menyiapkan video tutorial youtube tentang energi alternatif listrik dengan tenaga kentang.

\section{b. Pelaksanaan}

Adapun pelaksanaan tindakan berupa pembelajaran IPA pada kompetensi menjelaskan cara menghasilkan, menyalurkan, dan menghemat energi listrik adalah sebagai berikut :

1) Kegiatan awal

- Melalui Zoom guru bersama siswa saling memberi dan menjawab salam ( Kolaborasi -4C )

- Melalui Zoom guru melakukan absensi dan bertanya kesehatan

- Melalui Zoom guru dan siswa berdoa yang dipimpin bersama.

- Melalui Zoom siswa bersama guru menyanyikan lagu Indonesia Raya 
- Melalui Zoom guru dan siswa bertanya jawab tentang materi pembelajaran

- Sebagai seorang pelajar, apa peran kita untuk Bangsa Indonesia

\section{Planing (Perencanaan)}

- Guru menyampaikan materi dan tujuan pembelajaran Daring hari ini.

2) Kegiatan Inti

- Melalui Zoom Guru menanyakan masalah untuk dipecahkan siswa “Apa peran bangsa Indonesia di mata Dunia terutama di lingkup ASEAN ?”

\section{Creating}

- $\quad$ Siswa mengamati teks eksplanasi yang disajikan

oleh guru berjudul “ Indonesia Luncurkan Program Akademi Energi Surya Pertama di Indonesia "dalam bentuk power point ( TPACK)

- Dari teks eksplanasi yang disajikan, siswa menelaah isi teks tersebut berupa
a. Topik masalah pada paragraf ke-1.
b. Deret penjelas pada paragraf ke-2
c. Kesimpulan pada paragraf ke-3

- Siswa diberi kesempatan untuk bertanya tentang materi dan tugas yang diberikan

- Siswa mempresentasikan hasil telaah isi teks ekplanasi yang disajikan

- Melalui Zoom, siswa dan guru mengamati video youtube tentang peran Indonesia di lingkup ASEAN. (https://youtu.be/tfWX16mGs6U)

- Siswa menelaah peran Indonesia di lingkup ASEAN

- Siswa menunjukkan hasil telaah berupa peran Indonesia di lingkup ASEAN ke dalam buku tulis dan mengumpulkan melalui whatsapp grup

- Melalui zoom, siswa dan guru mengamati sumber energi alternatif yaitu sel surya

\section{Creating}

- Melalui Zoom, siswa dan guru mengamati bahan-bahan dan langkah yang akan digunakan dalam percobaan.

- Melalui Zoom, siswa dan guru menyaksikan video youtube listrik tenaga kentang. https://youtu.be/DWd8oAKJrAu

\section{Processing}

- Melalui Zoom siswa melakukan percobaan listrik tenaga kentang sesuai dengan video youtube.

- Melalui Zoom,siswa menyampaikan kesimpulan hasil percobaan dari video youtube.

- Melalui Zoom, siswa mendengarkan penjelasan guru tentang penyusunan laporan hasil percobaan 
- Melalui Zoom, siswa mengamati sekilas LKPD dari guru yang dikirim lewat pesan whatsapp.

- Melalui Zoom, siswa diberi penjelasan mengenai teknik dan waktu pengumpulan hasil rekaman percobaan energi alternatif listrik dengan jeruk.

- Melalui Zoom ,siswa diberikan soal untuk pemantapan materi yang dikirim melalui whatsaap .

\section{3) Kegiatan Penutup}

- Melalui zoom siswa dan guru melakukan refleksi pembelajaran.

- Melalui zoom Siswa bersama guru membuat kesimpulan.

- Melalui zoom Siswa dan guru menyanyikan lagu " Gundul-gundul Pacul “.

- Melalui zoom Guru mengingatkan untuk selalu bekerja sama dan menghargai teman.

- Melalui zoom Kegiatan ditutup dengan doa dan salam.

Data kreativitas siswa diperoleh dari pengamatan terhadap aktivitas siswa selama proses pembelajaran berlangsung. Adapun data hasil pengamatan aktivitas siswa pada siklus 1 dapat diketahui pada Lembar Observasi kreativitas Siswa pada kegiatan percobaan Sumber Energi Alternatif Listrik. Data hasil pengamatan tersebut diolah peneliti sehingga diperoleh skor rata-rata kreativitas siswa pada tiap-tiap aspek selama pembelajaran pada Siklus I adalah 55\%.

\section{c. Observasi}

Dalam melakukan tindakan penelitian pada siklus I, peneliti menggunakan video turorial dari youtube. Dari pembelajaran yang telah dilaksanakan didapatkan data hasil pengamatan dan kreativitas siswa. Dari data tersebut diperoleh bahwa kreativitas siswa yang mencapai di atas KKM adalah 44,4 \% atau sebanyak 8 siswa yang mampu melaksanakan percobaan dan membuat lapran hasil percobaan dengan benar dan 55,6\% atau 10 siswa belum mampu berkreativitas dalam melaksanakan percobaan dan membuat lapran hasil percobaan.

\section{d. Refleksi}

Dari hasil pembelajaran yang telah dilaksanakan akan diperoleh tentang kelebihan dan kekurangan pada siklus I. Dengan menngunakan video tutorial youtube secara mandiri siswa belum mampu berkreativitas dalama melaksanakan dan membuat laporan hasil percobaan. Hasil data dari siklus ini digunakan sebagai pedoman untuk menyusun tindakan pada siklus II. 


\section{Deskripsi Siklus II}

Dalam melakukan tindakan penelitian pada siklus II, peneliti menggunakan model pembelajaran Discovery Learning dan metode Demonstrasi. Dari pembelajaran yang telah dilaksanakan didapatkan data hasil pengamatan dan kreativitas siswa. Dari data tersebut diperoleh bahwa kreativitas siswa yang mencapai di atas KKM (75) adalah 94,4\% atau sebanyak 17 siswa yang mampu melaksanakan percobaan dan membuat lapran hasil percobaan dengan benar dan 5,6 \% atau 1 siswa masih kurang dalam berkreativitas dalam melaksanakan percobaan dan membuat laporan hasil percobaan.

Dari hasil pembelajaran yang telah dilaksanakan akan diperoleh tentang kelebihan dan kekurangan pada siklus II. Dengan menggunakan model pembelajaran discovery learning berbantuan demonstrasi siswa mampu berkreativitas dalama melaksanakan dan membuat laporan hasil percobaan. Dari hasil data siklus ini tingakt kreativitas siswa sudah meningkat sehingga peneliti merasa tidak perlu untuk melakukan siklus selanjutnya.

Hasil penilaian kreativitas siswa dalam melakukan dan membuat laporan hasil percobaan pada pembelajaran yang menerapkan model Discovery Learning dan metode demonstrasi mengalami peningkatan yang sangat signifikan yaitu sebanyak $50 \%$. Hal ini dibuktikan dengan hasil penelitan yang digambarkan pada diagram dibawah ini.

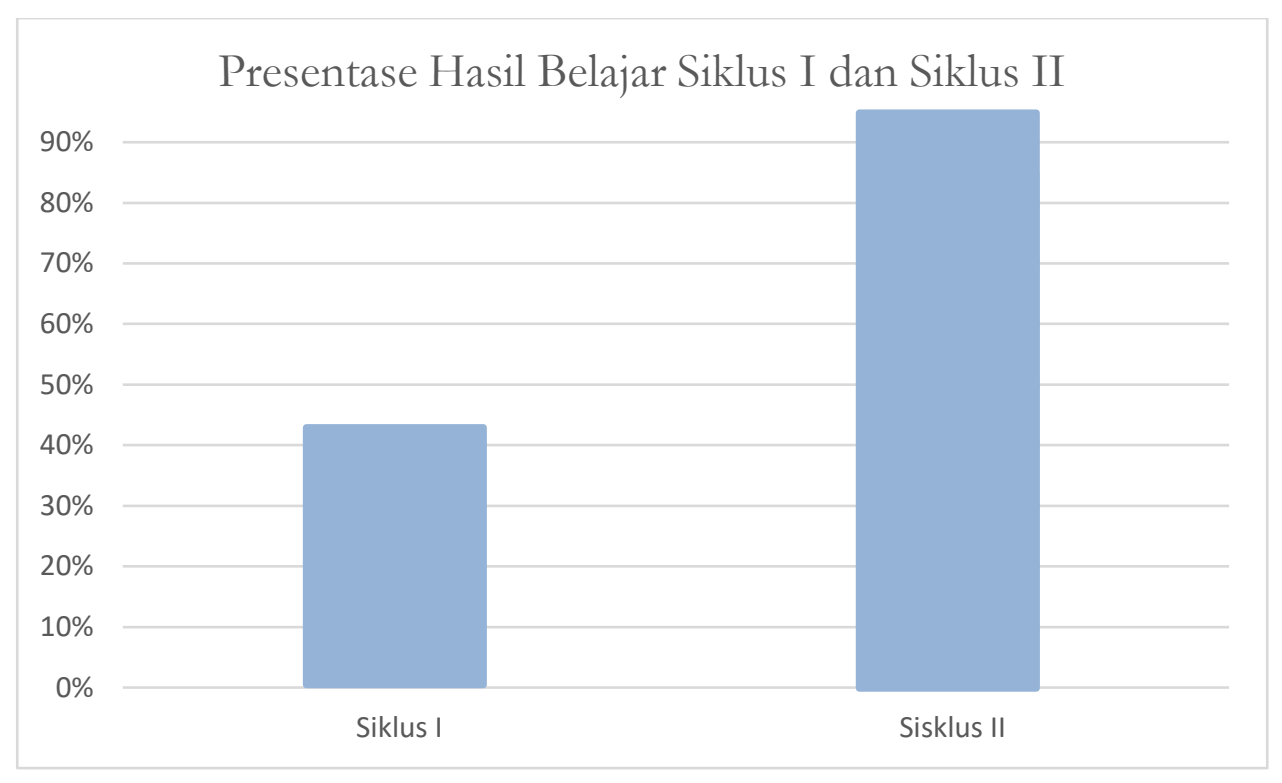

Gambar 2. Peningkatan Persentase Kreatifitas Siswa

Berdasarkan Diagram di atas dapat diketahui bahwa pada Siklus I persentase ketuntasan siswa secara klasikal memeroleh 44,4\%. Persentase ketuntasan tersebut belum memenuhi indikator penelitian yaitu $\geq 75 \%$. Sedangkan pada Siklus II persentase ketuntasan kemampuan pemecahan masalah siswa mencapai 94,4\%. Persentase ketuntasan pada Siklus II telah memenuhi indikator penelitian. Dengan demikian dapat 
disimpulkan bahwa kreatifitas siswa dalam melakukan dan membuat laporan hasil percobaan dari Siklus I ke Siklus II mengalami peningkatan sebesar 50\%.

Peningkatan kreatifitas siswa dalam membuat melakukan dan membuat laporan hasil percobaan pada setiap siklus membuktikan keefektifan penerapan model pembelajaran discovery learning dan metode demonstrasi memberikan semangat kepada siswa sehingga siswa tertarik menerima pembelajaran dan bekerja sama di dalam kelas serta lebih kreatif, dan menyenangkan baik bagi guru maupun bagi siswa, mudah di pahami dan mudah diingat sehingga siswa cenderung mendapat nilai yang baik. Hal ini sejalan dengan penelitian Suwandari, dkk (2019) yang menyatakan bahwa penerpan discovery learning efektif terhadap kreativitas siswa sekolah dasar.a

Peneliti menyimpulkan apabila model pembelajaran discovery Learning dan metode demonstrasi ini diterapkan terus menerus maka akan dapat meningkatkan hasil belajar. Hal ini sejalan dengan hukum latihan (law of exercise) dalam teori belajar Koneksionisme yang dikemukakan oleh Thorndike bahwa hubungan stimulus dan respons akan semakin kuat manakala terus menerus dilatih atau diulang; sebaliknya hubungan stimulus respons akan semakin lemah manakala tidak pernah diulang (Kirom, 2017; Cox, 2018; Sulfemi, 2019; Juniarso, 2020).

\section{KESIMPULAN}

Penerapan discovery learning berbantuan demonstrasi dapat meningkatkan kreativitas siswa sekolah dasar dalam menghasilkan energi alternatif listrik. Oleh karena itu, model pembelajaran discovery learning dapat dijadikan sebagai pilihan pembelajaran inovatif di sekolah dasar untuk memperbaiki kreatifitas siswa.

\section{DAFTAR PUSTAKA}

Aisyah, S., Danuwijaya, A. A., Abdullah, A. G., Yuliani, G., \& Munawaroh, H. S. H. (2017). Ideas for 21st Century Education: Proceedings of the Asian Education Symposium (AES 2016), November 22-23, 2016, Bandung, Indonesia. I. Hamidah (Ed.). Routledge.

Cox, B. D. (2018). The Place for Dewey's Constructivism of Intelligent Action in the American Meritocracy of Thorndike. In Constructivist Education in an Age of Accountability (pp. 21-55). Palgrave Macmillan, Cham.

Fanny, A. M. (2019, March). Analysis Of Pedagogical Skills And Readiness Of Elementary School Teachers In Support Of The Implementation Of The 2013 Curriculum. In International Conference on Bussiness Law and Pedagogy (Vol. 1, No. 1, pp. 59-63).

Istiqomah, N. (2019). Penerapan Metode Demonstrasi Untuk Meningkatkan Kreativitas Berfikir Siswa Pada Materi Larutan Elektrolit Dan Non Elektrolit Kelas X Di SMAN 1 Tinombo Selatan (Doctoral dissertation, Universitas Tadulako).

Juniarso, T. (2020). Model Discovery Learning Terhadap Kemampuan Berpikir Kreatif Mahasiswa. ELSE (Elementary School Education Journal): Jurnal Pendidikan dan Pembelajaran Sekolah Dasar, 4(1), 36-43.

Kirom, A. (2017). Implementasi Model Pembelajaran Discovery Learning Dalam Peningkatan Keterampilan Siswa Bermain Bolavoli Pada Mata Pelajaran PJOK Di SMA Negeri Blega Bangkalan. Buana Pendidikan: Jurnal Fakultas Keguruan dan Ilmu Pendidikan, 13(24), 99-108.

Marliyah, S. (2019). Pengaruh Penggunaan Model Inquiry Learning Dan Discovery Learning Terhadap Prestasi Belajar Ipa Siswa Kelas VI SD Ditinjau Dari Motivasi Belajar. Jumal Education And Development, 7(2), 169169.

Prasasti, D. E., Koeswanti, H. D., \& Giarti, S. (2019). Peningkatan Keterampilan Berpikir Kritis Dan Hasil 
Belajar Matematika Melalui Model Discovery Learning Di Kelas Iv Sd. Jurnal Basicedu, 3(1), 174-179.

Rahman, M. H. (2017). Using discovery learning to encourage creative thinking. International Journal of Social Sciences \& Educational Studies, 4(2), 98.

Rusdi, R. (2018). Implementasi Teori Kreativitas Graham Wallas Dalam Sekolah Kepenulisan di Pesantren Mahasiswa Hasyim Asy'ari Cabeyan Yogyakarta. Muslim Heritage, 2(2), 259-274.

Siswono, T. Y. E. (2019, October). Pembelajaran Matematika Di Era Revolusi Industri. In Prosiding Seminar Nasional Pendidikan Matematika II (SNPMAT II): Pembelajaran Matematika dalam Era Revolusi Industri 4.0 (p. 1). Universitas Halu Oleo Press.

Sulfemi, W. B. (2019). Penerapan Model Pembelajaran Discovery Learning Meningkatkan Motivasi Dan Hasil Belajar Pendidikan Kewarganegaraan. Jurnal Rontal Keilmuan Pancasila dan Kewarganegaraan, 5(1).

Susmiati, E. (2020). Meningkatkan Motivasi Belajar Bahasa Indonesia Melalui Penerapan Model Discovery Learning dan Media Video Dalam Kondisi Pandemi Covid-19 bagi Siswa SMPN 2 Gangga. Jurnal Paedagogy, 7(3), 210-215.

Suwandari, S., Ibrahim, M., \& Widodo, W. (2019). Application of Discovery Learning to Train the Creative Thinking Skills of Elementary School Student. International Journal of Innovative Science and Research Technology, 4(12), 410-417.

Trung, T. (2014). Discovery learning with the help of the geogebra dynamic geometry software. International Journal of Learning, Teaching and Educational Research, 7(1). 